\title{
POLÍTICAS DE GESTÃO DE PESSOAS DESTINADAS AOS PROFISSIONAIS COM DEFICIENNCIA: UM ESTUDO EM UMA ORGANIZACÃO HOTELEIRA DA CIDADE DO RIO DE JANEIRO
}

\author{
PERSONNEL MANAGEMENT POLICIES FOR PEOPLE WITH DISABILITIES: A STUDY IN A HOTEL \\ ORGANIZATION IN THE CITY OF RIO DE JANEIRO
}

POLÍTICAS DE GESTIÓN DE PERSONAS DESTINADAS A LOS PROFESIONALES CON

DISCAPACIDAD: UN ESTUDIO EN UNA ORGANIZACIÓN HOTELERA DE LA CIUDAD DE RÍO DE JANEIRO

Marta Pereira Forte Araújo

Universidade Federal Fluminense (UFF) martapfa@gmail.com

Graduação em Turismo pela Universidade Federal Fluminense (UFF)

\section{Carolina Lescura de Carvalho Castro \\ Universidade Federal Fluminense (UFF) \\ carolescura@gmail.com}

Doutorado em Administração pela Universidade Federal de Lavras (UFLA)

Mestrado em Administração pela Universidade Federal de Lavras (UFLA)

Especialização em Gestão de Negócios pela Universidade Federal de Juiz de Fora (UFJF)

Graduação em Turismo pela Universidade Federal de Juiz de Fora (UFJF)

Data de Submissão: 20/09/2012

Data de Aprovação: 13/05/2013

\section{RESUMO}

A inserção profissional de pessoas com deficiência nas organizações tem sido tema de vários estudos acadêmicos. Entretanto se nota que há poucos estudos referentes à inserção desse profissional em empreendimentos turísticos. Tendo constatado tal fato, o objetivo deste estudo é analisar as políticas de gestão de pessoas da organização hoteleira Alfa para os profissionais que possuem deficiência. O referencial teórico construído discute o processo de inserção de pessoas com deficiência no mercado de trabalho. Com relação à pesquisa de campo, a unidade de investigação constitui-se de um hotel pertencente a uma rede hoteleira com forte atuação no mercado nacional e internacional. Os resultados da pesquisa revelam que a inserção desses profissionais no mercado, especificamente no ramo hoteleiro, merece uma reflexão muito mais aprofundada, não apenas no âmbito acadêmico, mas, sobretudo, na natureza prática das ações dos gestores. Evidencia-se que a contratação desses profissionais traz muitos benefícios para a organização no que tange ao ganho de uma imagem corporativa positiva. No entanto é fundamental que as empresas desvencilhem-se dessa visão instrumental e agucem para o aprendizado oriundo dessa experiência, de promover a diversidade organizacional.

PALAVRAS-CHAVE: Setor hoteleiro. Pessoas com deficiência. Gestão da diversidade.

ABSTRACT

The professional inclusion of people with disabilities in organizations has been the subject of numerous academic studies. However, there are few studies concerning the inclusion of this professional in tourist 
developments. In view of this fact, the general objective of this study is to analyze the personnel management policies of the Alfa hotel organization for professionals with disabilities. The theoretical framework discusses the process of inclusion of people with disabilities in the labor market. With regard to field research, the research unit was a hotel that belongs to a hotel chain with a strong presence in domestic and international markets. The research results reveal that the inclusion of these professionals in the labor market, specifically in the hotel industry, deserves much deeper reflection, not only in the academic sphere, but especially in the practical nature of the managers' actions. It is evident that recruiting these professionals brings many benefits for the organization, such as gains in positive corporate image. However, it is essential that companies relinquish the instrumental view and promote experience-based learning, in order to promote organizational diversity.

KEYWORDS: Hotel sector. Person with disability. Diversity management.

\section{RESUMEN}

La inserción profesional de personas con discapacidad en las organizaciones ha sido tema de varios estudios académicos. Sin embargo, se nota que hay pocos estudios referentes a la inserción de estos profesionales en emprendimientos turísticos. Habiendo constatado este hecho, el objetivo de este estudio es analizar las políticas de gestión de personas de la organización hotelera Alfa para los profesionales con discapacidad. El referente teórico construido discute el proceso de inserción de personas con discapacidad en el mercado de trabajo. En relación a la investigación de campo, la unidad de investigación está constituida por un hotel perteneciente a una red hotelera con fuerte actuación en el mercado nacional e internacional. Los resultados de la investigación revelan que la inserción de estos profesionales en el mercado, específicamente en el rubro hotelero, merece una reflexión mucho más profunda, no solamente en el ámbito académico sino, sobre todo, en la naturaleza práctica de las acciones de los gestores. Resulta evidente que la contratación de estos profesionales trae muchos beneficios para la organización en lo que se refiere a ganar una imagen corporativa positiva. No obstante, es fundamental que las empresas se liberen de esa visión instrumental y apunten hacia un aprendizaje oriundo de esa experiencia, de promover la diversidad organizacional.

PALABRAS CLAVE: Sector hotelero. Personas con discapacidad. Gestión de la diversidade.

\section{INTRODUÇÃO}

O turismo é uma atividade que trabalha com o sonho das pessoas. Há uma busca constante em atender todos os tipos de consumidores e, assim, oferecer um serviço personalizado.

Nos últimos anos, os empreendimentos turísticos passaram a se estruturar para receber um público que necessita de cuidado especial, são elas as pessoas com deficiência (PcD). Ocorreram mudanças na preparação do ambiente para recebê-las, ou seja, criou-se um espaço mais acessível. Porém é notório que a adequação arquitetônica foi pensada essencialmente para atender às necessidades e aos anseios dos clientes.

Sabe-se que a atividade turística é uma das maiores fontes geradoras de empregos diretos e indiretos. Porém, no mercado de trabalho, ainda há resquícios de uma sociedade que menospreza a diversidade dentro de suas organizações. E uma parcela da sociedade permanece marginalizada, em detrimento da raça, da orientação sexual, do gênero, da deficiência, dentre outras razões. Essa realidade também está presente nos empreendimentos turísticos.

Tratando especialmente da discriminação relacionada à pessoa com deficiência (PcD), verifica-se que sua origem advém da antiguidade. Período em que essas pessoas eram tidas como inválidas e incapazes de prover seu próprio sustento. Apesar de a discriminação ter diminuído, ainda há muito preconceito com relação ao potencial desse profissional (BAHIA, 2006; PEREIRA, 2006). 
Reconhece-se que as empresas inserem os profissionais com deficiência no mercado de trabalho, mesmo que seja para cumprir a legislação (BAHIA, 2006; CARVALHO-FREITAS, 2007; CARNEIRO; RIBEIRO, 2008; VILLE; WINANCE, 2006). Sabe-se que as diferenças dentro de uma organização tendem a gerar benefícios para a empresa e também para os seus funcionários. No entanto lidar com a diversidade exige um modelo de gestão de pessoas capaz de gerenciar as diferenças de forma que não haja discriminação por raça, etnia, sexo e demais características. Esse modelo deve ser capaz de suprir as necessidades especiais dos deficientes. A gestão da diversidade eficiente é um dos maiores desafios vivenciados nas organizações. É notório que parte da sociedade brasileira apresenta preconceito arraigado com relação às minorias e mudar esse comportamento dentro das empresas não é uma tarefa simples (BAHIA, 2006; SOBRAL; PECI, 2008).

O compromisso social torna-se um diferencial para as organizações. A inserção de PCD no mercado de trabalho torna a imagem da empresa valorizada diante dos próprios funcionários, fornecedores e clientes. O que propicia valor agregado em tempos de competitividade (REIS, 2007; TACHIZAWA; ANDRADE, 2008; SARAIVA; IRIGARAY, 2009).

Desse modo, o objetivo deste artigo é analisar as políticas de gestão de pessoas da organização hoteleira Alfa para os profissionais que possuem deficiência.

O presente trabalho encontra-se organizado da seguinte forma: a próxima seção tratará das transformações que as organizações sofreram para atender às mudanças globais. Dentre essas modificações, destaca-se a incorporação do discurso de responsabilidade social. Mais adiante, será abordada a temática da diversidade organizacional, cedendo atenção especial aos profissionais com deficiência. Posteriormente, serão discutidas algumas questões referentes à inserção dessas pessoas no mercado de trabalho. Logo mais, apresenta-se o percurso metodológico adotado neste artigo, bem como as categorias de análise resultantes da pesquisa de campo.

\section{TRANSFORMAÇÕES NO UNIVERSO ORGANIZACIONAL E LEGITIMAÇÃO DO "SOCIALMENTE RESPONSÁVEL"}

A sociedade viveu recorrentes transformações no século XX. Essas transformações englobaram o setor empresarial e mudaram o modo como as organizações passaram a gerir seus negócios. Segundo Hanashiro (2008), é possível dividir esse processo em três etapas: era industrial; era pós-industrial; e era informacional.

A era industrial surge a partir do século XVIII. Nessa fase, o processo artesanal de produção foi substituído pelo modelo industrial, dando início à sociedade industrial. Acreditava-se que, para alcançar a otimização dos recursos e dos fatores de produção, havia apenas one best way, ou seja, ser produtivo e eficiente eram as características necessárias para que a meta de produção fosse atingida (HANASHIRO, 2008).

Já o período pós-industrial, que se inicia na metade do século $X X$, mantém a industrialização, contudo o setor de serviços começa a se desabrochar. Outra mudança que se faz perceptível nessa era trata da valorização dos bens intangíveis, tais como: conhecimento e criatividade. O mercado começa a focar na inovação, alta qualidade e baixo custo como meio de garantir a competitividade. A tecnologia industrial passa a ser utilizada para a produção, deixando de lado a inflexibilidade da produção da era industrial (HANASHIRO, 2008).

A era informacional ocorre a partir dos anos de 1990. O mundo torna-se uma aldeia global no qual todos estão integrados. Devido ao alto uso da tecnologia da informação, a competitividade fica cada vez mais acirrada no mundo coorporativo. O conhecimento é classificado como o recurso mais importante e se torna valorizado dentro das organizações. Nessa fase, é notório o crescimento do setor de serviços devido à migração oriunda do setor industrial. O modo de gerir os recursos sofre algumas alterações juntamente como o meio. As tarefas operacionais, bem como as burocráticas, são incumbidas a terceiros por meio da terceirização (HANASHIRO, 2008).

A era informacional contribuiu para a revolução do tempo, do espaço e da comunicação na sociedade. Por essa razão, as comunicações tornam-se cada vez mais instantâneas e interativas. Pode-se citar a virtualização como fruto desse processo tecnológico, cuja presença do indivíduo vai 
além das fronteiras espaciais. Ou seja, a distância geográfica não é obstáculo para manter os indivíduos unidos por interesses comuns. Tais modificações impactam também o comportamento do consumidor, que passa a ter mais acesso às informações, dando-lhes maior poder de julgamento (HANASHIRO, 2008).

O processo tecnológico traz consigo muitos benefícios, porém é importante considerar que, em meio aos benefícios, existem também os desafios. Um dos desafios que causa maior impacto nas organizações se trata da globalização. Assim, o aumento da competitividade é inevitável, bem como o aumento de consumidores mais exigentes. Com a diversidade da mão de obra, os administradores devem compreender os diferentes modelos culturais, respeitando os costumes e as tradições das pessoas que atuam em suas organizações (SOBRAL; PECI, 2008).

Nessa discussão, vale ressaltar que as empresas que apostam em tecnologia ou em qualquer outro elemento passível de imitação, como fonte de vantagem competitiva, logo perdem espaço no mercado para as suas concorrentes, já que estas são capazes de investir nos mesmos recursos tecnológicos (WAGNER III; HOLLENBECK, 2003; VIEIRA; OLIVIERA, 1999; HANASHIRO, 2008). Nesse sentido, o que é considerado como vantagem competitiva sustentável dentro das organizações são as pessoas, visto que capacidades, conhecimentos, habilidades, criatividade, inteligência e experiências individuais são dificilmente imitadas, ou seja, reproduzidas com exata perfeição (HANASHIRO, 2008).

Além desses aspectos característicos do período denominado de informacional, é possível mencionar a preocupação das empresas com a projeção de uma imagem socialmente responsável.

Daft (1999) e Churchill e Peter (2000) afirmam que a responsabilidade social é a obrigação que a empresa tem de prover o bem-estar da sociedade, bem como tomar decisões que cause nenhum ou pouco impacto negativo na sociedade.

Drucker (2002, p. 556) afirma que se trata do que "[...] a empresa pode ou deve fazer para enfrentar e resolver os problemas da sociedade", bem como a contribuição que "[...] a empresa pode prestar a problemas sociais como discriminação (...), a manutenção e recuperação do meio ambiente".

Já o Instituto Ethos (2011, s.p.) declara que:

\begin{abstract}
Responsabilidade social empresarial é a forma de gestão que se define pela relação ética e transparente da empresa com todos os públicos com os quais ela se relaciona e pelo estabelecimento de metas empresariais que impulsionem o desenvolvimento sustentável da sociedade, preservando recursos ambientais e culturais para as gerações futuras, respeitando a diversidade e promovendo a redução das desigualdades sociais.
\end{abstract}

Uma das motivações para uma empresa aderir à responsabilidade social se deve à competitividade que redireciona o poder para as mãos do novo consumidor. Segundo Tachizawa e Andrade (2008, p. 2), o novo consumidor busca "[...] interagir com organizações que sejam éticas, que tenham boa imagem institucional no mercado e que atuem de forma socioambientalmente responsável".

Em um ambiente competitivo, as empresas investem em ações sociais, a fim de promover a imagem da empresa. Segundo Reis (2007, p. 172), "é compreensível e até natural que aliem ações sociais destinadas a beneficiar segmentos da população com a melhoria do próprio conceito institucional".

Alguns autores atribuem a responsabilidade social ao compromisso da empresa para com o desenvolvimento, o bem-estar e a qualidade de vida de seus funcionários, família e sociedade em geral (JARAMILLO; ANGEL, 1996 apud ASHLEY, 2002). Portanto, adotar uma postura "socialmente responsável" inclui, sobretudo, valorizar o cliente interno, promovendo um ambiente de trabalho harmonioso. Desta forma, uma das temáticas que tem ganhado crescente espaço nas discussões acadêmicas e gerenciais é a adesão da diversidade no espaço laboral.

\title{
DIVERSIDADE NAS EMPRESAS: COMPREENDENDO OS PROFISSIONAIS COM DEFICIÊNCIA
}

A prática da diversidade tem ganhado destaque nos estudos organizacionais (SHORE et al., 2009; BROOKS; EDWARDS, 2009; EMSLIE; HUNT, 2009; CAMPBELL, 2002; PEREIRA; HANASHIRO, 2010; WARD; WINSTANLEY, 2006; SCOTT, 2005; MYERS, 2003). Devido ao processo de globalização 
vivenciado nos dias de hoje, torna-se comum a presença de pessoas com diferentes características atuando dentro das organizações. Dado este fato, a literatura acadêmica busca estudar e compreender a heterogeneidade dentro das empresas. Mais do que isso, busca meios de gerir a diversidade, fazendo o uso práticas que elevem o bem-estar dos funcionários em todos os sentidos.

Por heterogeneidade pode-se considerar aspectos como gênero, etnia, religião, orientação sexual, história, estilo de vida, crença, idade ou limitações físicas (ALVES; GALEÃO-SILVA, 2004; SARAIVA; IRIGARAY, 2009; PEREIRA; HANASHIRO, 2010; NKOMO; COX JUNIOR, 2007). Nesse contexto, tem-se que a diversidade é tudo aquilo que foge ao que é considerado padrão pela sociedade. Há muito que se aprender sobre a diversidade, mais especificamente sobre a deficiência. Mas o que seria deficiência? Pereira (2006) afirma que cada cultura e época possuem sua própria concepção acerca da deficiência. No entanto Santos $(2008,502)$ compreende que "deficiência é um conceito abrangente relacionado a restrições sociais impostas às pessoas que possuem variedade nas habilidades corporais". Já o Decreto 3.298, de 20 de dezembro de 1999 (BRASIL, 1999), apresenta a seguinte definição para deficiência em seu artigo 30: "Toda perda ou anormalidade de uma estrutura ou função psicológica, fisiológica ou anatômica que gere incapacidade para o desempenho de atividade, dentro do padrão considerado normal para o ser humano".

No entanto, para o escopo desse trabalho, focar-se-á na diversidade voltada para as pessoas com deficiência (PCD), na qual estão incluídas as pessoas com deficiência física e sensorial. Como Carvalho-Freitas (2007) sugere, não se adotará a expressão pessoas com necessidades especiais, pois esse termo engloba todas as pessoas que carecem de um tratamento especial, como, por exemplo: mulheres grávidas, obesos, idosos, entre outros. Tampouco será utilizado o termo deficiente por ser uma palavra agressiva. Sassaki (2002) complementa que o termo pessoas portadoras de deficiência está em desuso já que a pessoa possui uma deficiência e não a porta. O autor ainda esclarece que utilizar a termologia correta não se trata apenas de semântica, mas sim de evitar estereótipos, estigmas e preconceitos.

A discriminação que as PcD sofrem tem sua origem na antiguidade. A deficiência era vista como um fardo ou comparada à morte na Idade Antiga. Durante esse período, as pessoas eram tidas como inválidas e incapazes de prover seu próprio sustento. Há muitos registros históricos que narram sobre as pessoas com deficiência. Sabe-se que, no Egito Antigo, as deficiências eram vistas como males; o preconceito e a discriminação surgiram com os hebreus que consideravam a deficiência como resultado da impureza e do pecado. Os gregos acreditavam que as PcD tinham poderes místicos, porém, quando se tratava das crianças, era uma prática corriqueira a eliminação de todas elas. Os romanos, por sua vez, classificaram de monstruosidade a deficiência (BAHIA, 2006; PEREIRA, 2006).

Com relação ao Brasil, Bahia (2006) comenta que foi no governo Getúlio Vargas (1930/1945) que surgiu os primeiros indícios de preocupação com as pessoas com deficiência. Buscou-se envolvêlas mais na sociedade, oferecendo-Ihes acesso à educação, à reabilitação, à profissionalização e à inserção no mercado de trabalho. Com a Consolidação das Leis de Trabalho (CLT), as políticas assistencialistas voltadas para as pessoas com deficiência foram implementadas.

No âmbito do trabalho, por volta de 1980, surgiu o paradigma da Integração que estabelecia a contração de pessoas com deficiência que fossem aptas a conviver em uma sociedade repleta de barreiras arquitetônicas e atitudinais. Ou seja, a pessoa com deficiência teria de se adaptar à sociedade. Apenas na década de 90 que o paradigma da Integração dá lugar à Inclusão. As práticas de inclusão começam a se desabrochar, lembrando que a sociedade é que deve se preparar para conviver e atender às pessoas com deficiência. Vale ressaltar que a contratação da PcD deve ocorrer independente de sua deficiência, desde que ela esteja qualificada profissionalmente para desenvolver a sua função. Sob essa ótica, um dos deveres das organizações é reduzir ou eliminar as barreiras que prejudiquem as pessoas no acesso ao trabalho (BAHIA, 2006; BAHIA \& SCHOMMER, 2009).

Apesar de se ter alcançado muitas conquistas, não se pode dizer o mesmo acerca das mudanças na sociedade, pois se tratando de cultura e mudanças sociais, o processo se mostra mais delongado. Corrobora Pereira (2006, p. 32 e 33) ao afirmar que:

Nesse ponto há que se estabelecer a diferença entre conquistas e mudanças. É inquestionável que muitas conquistas têm efetivamente ocorrido nesse período recente, mas as mudanças propriamente ditas requerem muito mais tempo. A imagem social da pessoa com deficiência, 
assim como a sua auto-imagem e todo o preconceito e discriminação que ela sofre e que sente em relação aos seus iguais e diferentes, em nada se alteram com um decreto político ou com a mobilização nacional. Esses aspectos são da ordem da cultura, pode-se dizer da ordem da "cultura da deficiência", incluindo aí a condição de diferente, incapaz, inválido, inferior, primeiramente imposta, e, posteriormente, assimilada pelo próprio indivíduo.

Apesar de a discriminação ter diminuído, ainda há muito preconceito com relação às pessoas com deficiência, bem como ao seu potencial profissional. Bahia (2006) ressalta que, desconstruir a imagem de que a pessoa com deficiência seja vista como um sujeito improdutivo e incapaz é o grande desafio da sociedade. Neri et al. (2003) ressaltam que as limitações físicas, sensoriais ou mentais não incapacitam e nem mesmo colocam em desvantagem as PcDs, contudo essas características podem acarretar inferioridades individuais e coletivas, o que caracteriza a deficiência como algo social.

Como visto, em meio às tendências organizacionais surgem políticas de inserção social de pessoas com deficiência no mercado de trabalho. Essa inserção, muitas das vezes, está pautada na responsabilidade social ou imposta pela legislação brasileira.

\section{O INGRESSO NO MERCADO DE TRABALHO}

O trabalho tem grande importância na vida dos seres humanos, pois por meio dele o indivíduo se insere na sociedade e é capaz de prover seu próprio sustento. Ardichvili e Kuchinke (2009) salientam que o trabalho extravasa a simples subsistência, pois ele é capaz de conceder sentido à vida das pessoas, promovendo autoestima, identidade e bem-estar psicológico. Corroborando com essa perspectiva psicológica acerca do trabalho, Giordano (2000, p. 53) afirma que:

\footnotetext{
Por meio do trabalho, o homem adquire sua identidade social e atende às necessidades básicas de segurança, autonomia, afirmação, auto-realização, prazer, auto-estima, dentre outras tantas, caracterizando, portanto, um dos mais valiosos recursos de adaptação do homem ao meio.
}

O direito ao trabalho é assegurado a todos os homens pela legislação brasileira. As pessoas com deficiência são vistas como indivíduos improdutivos. Dessa forma, em 10 de junho de 1983, a Organização Internacional de Trabalho (OIT) convocou a Convenção Internacional $n^{\circ} 159^{1}$, que trata da necessidade de assegurar e favorecer o acesso de pessoas com deficiência ao mercado de trabalho, tanto em zonas rurais como nas urbanas, além de garantir igualdade de oportunidades a todas as PcDs, independentemente do tipo de deficiência (BAHIA, 2006). De acordo com Carneiro \& Ribeiro (2008), o Brasil ratificou a Convenção Internacional da OIT por meio da Lei no 7.853 , que foi editada em outubro de 1989 e instituiu as chamadas "Lei de Cotas" empregatícias por meio da Lei 8.213, 24 de julho de 1991. Esta lei determina que organizações que possuam 100 empregados ou mais devem contratar pessoas com deficiência (BRASIL, 1991), respeitando os percentuais dispostos na Tabela 1.

Tabela 1: Percentual de vagas direcionadas às pessoas com deficiência

\section{Número de empregados}

De 100 a 200

De 201 a 500

De 501 a 1.000

1.001 ou mais

\section{Percentual de vagas}

$2 \%$

$3 \%$

$4 \%$

$5 \%$

Fonte: BRASIL (1991).

A literatura acadêmica comprova que a principal ferramenta que garante a inserção das pessoas com deficiência no mercado de trabalho muitas vezes não é cumprida (CARVALHO-FREITAS, 2007; CARVALHO-FREITAS; MARQUES, 2007). As organizações que têm de inserir PcD para cumprir uma obrigação legal tende a usar o "jeitinho brasileiro" para contornar a situação. Carneiro e Ribeiro (2008) realizaram uma pesquisa referente às práticas das empresas frente à lei de cotas.

1 A Conferência Geral da Organização Internacional do Trabalho foi realizada em Genebra pelo Conselho de Admistração do Escritório Internacional do Trabalho, na qual foi adotada a Convenção nº 159 (BAHIA, 2006). 
Os autores verificaram que muitas empresas impõem barreiras para contratação de PcD. A prática mais adotada, segundo os autores, é disponibilizar vagas em que se exige um alto grau de qualificação, além de experiência profissional comprovada na carteira de trabalho. Um dos principais argumentos para a não contratação de pessoas com deficiência recai na questão da baixa qualificação profissional. Contudo as medidas adotadas com o intuito de burlar a lei não se restringem apenas à qualificação profissional. Algumas organizações contratam pessoas que possuem uma leve deficiência e as enquadram na lei de cotas (CARNEIRO; RIBEIRO, 2008). Essa é uma prática comum, haja vista que as empresas almejam contratar pessoas com deficiência "pouco complicadas" (BAHIA, 2006). Outra justificativa comumente utilizada trata da dificuldade de acessibilidade e adequação ao trabalho (CARVALHO-FREITAS, 2007).

Contudo é importante esclarecer que muitas organizações de fato cumprem a lei, seja por obrigação ou por motivação filantrópica. Bahia e Schommer (2009) citam que, para algumas organizações, a contratação de PcD é vista como uma estratégia de gestão, de modo a contribuir tanto para competitividade quanto para a sustentabilidade da organização e da sociedade. Ou seja, essas empresas são motivadas também por uma questão de cidadania. Já Saraiva e Irigaray (2009) observam que as organizações buscam aderir práticas organizacionais a fim de se legitimar socialmente perante o mercado. Elas adotam políticas não discriminatórias e, por meio desse discurso, promovem uma imagem de empresa socialmente responsável em comparação com as demais que não têm o mesmo posicionamento.

As empresas que se tornam inclusivas valorizam seu fator humano e buscam promover a qualidade de vida no trabalho. Dessa forma, facilitar o deslocamento de pessoas com deficiência em seu ambiente interno e externo se torna também responsabilidade das organizações (BAHIA; SCHOMMER, 2009), pois como observam Carvalho-Freitas et al., (2009, p. 2), é necessária a "adequação das condições e instrumentos de trabalho para potencializar as possibilidades de atuação das pessoas com deficiência."

A inserção profissional de pessoas com deficiência evidencia a importância do engajamento do governo e das organizações para cumprirem seu papel na sociedade. Facilitar a acessibilidade é uma questão de cidadania. As PCD têm o direito de fazer parte da sociedade, pois são pessoas com sentimentos, sonhos e potenciais e não podem ser ignoradas e discriminadas por fugirem do que as organizações, ou melhor, a própria sociedade admite como "normal".

\section{METODOLOGIA}

Com o intuito de alcançar o objetivo proposto no presente trabalho, optou-se por realizar uma pesquisa qualitativa de caráter exploratório em uma organização hoteleira, com forte atuação no mercado nacional e internacional.

A natureza qualitativa privilegia os aspectos subjetivos do ambiente organizacional. O presente trabalho foca em um tema delicado, a inserção de pessoas com deficiência nas organizações. Triviños (1987) elucida que existe uma relação dinâmica entre mundo real e sujeito, e que a interpretação dos fenômenos e a atribuição dos significados são essenciais nas pesquisas desse caráter. Godoi e Balsani (2006) apontam que a linguagem recebe uma centralidade neste tipo de investigação, visto que é por meio da comunicação e do processo interativo que as pessoas atribuem significados ao meio social.

Com relação à coleta de dados, utilizou-se a entrevista semiestruturada e a análise documental. Durante a entrevista não foi permitida a gravação das entrevistas, devido à ordem superior do empreendimento em que foi realizada a investigação. As respostas dos entrevistados foram anotadas. A fim de evitar que grande volume de informação fosse perdido, foi solicitado aos entrevistados que falassem pausadamente para que, assim, a anotação fosse realizada.

Para a análise dos dados, optou-se pela análise de conteúdo (BARDIN, 2011), a qual possibilitou captar os aspectos centrais revelados nas entrevistas. Para a escolha dos atores entrevistados, levou-se em consideração a necessidade de estudar as organizações hoteleiras que possuíssem mais de cem funcionários em seu quadro de pessoal. Conforme dito anteriormente, a "Lei de Cotas" estabelece que as empresas que possuam cem funcionários ou mais devem contratar pessoas com deficiência. Foram contatados via e-mail ou telefone seis hotéis da cidade do Rio de Janeiro, dos 
quais cinco optaram por não aderir à pesquisa. Portanto o número de entrevistados se limitou a quatro pessoas, a saber: um gestor e três profissionais com deficiência.

Por uma questão ética em pesquisa, a identidade da organização e dos entrevistados será mantida em sigilo. Dessa forma, a organização será identificada como Rede Alfa e os entrevistados serão identificados por meio DA FUNÇÃO, SEGUIDA DE UMA NUMERAÇÃO, como pode ser visualizado na Figura 1.

Quadro 1 - Caracterização dos atores entrevistados

\begin{tabular}{|c|c|c|c|c|c|c|}
\hline \multicolumn{2}{|c|}{ Sujeito } & $\operatorname{Sexo}^{1}$ & Idade & Escolaridade & $\begin{array}{l}\text { Tempo de per- } \\
\text { manência na }\end{array}$ & Tipo de deficiência \\
\hline 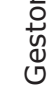 & Gestor 1 & N & 27 & 30 grau & 8 anos & \\
\hline \multirow{3}{*}{ 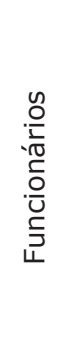 } & Funcionário 1 & 1 & 19 & 30 grau inc. & 9 meses & Física \\
\hline & Funcionária 2 & 2 & 23 & $2^{\circ} \mathrm{grau}$ & 1 ano e 5 meses & Física \\
\hline & Funcionária 3 & 3 & 38 & 30 grau inc. & 3 anos e 6 meses & Auditiva \\
\hline
\end{tabular}

Fonte: Dados da pesquisa.

Nota 1: M: Masculino; F: Feminino.

Os dados obtidos por meio das entrevistas e da análise de documentos permitiram a emergência de algumas categorias de análise que serão relatadas a seguir.

\section{ANÁLISE DOS RESULTADOS}

Por meio da análise de conteúdo foram criadas seis categorias, são elas: História de vida; Sentido do trabalho; Obrigação legal; Possíveis formas de burlar a lei; Acessibilidade; e Discriminação.

As categorias História de vida e Sentido do trabalho são referentes ao indivíduo, enquanto as demais categorias se referem à empresa.

\section{HISTÓRIA DE VIDA}

As entrevistas revelaram que os funcionários com deficiência tiveram um lar feliz e contavam com o apoio de seus familiares. Contudo se percebe que as dificuldades começaram a surgir na infância. Esses funcionários não estudaram em escolas exclusivas para PcD. Por serem considerados diferentes dos demais alunos, alguns deles sofreram com brincadeiras de mau gosto no período escolar.

\footnotetext{
Algumas crianças riam de mim e me davam alguns apelidos. (...) Minha mãe dizia para não ligar porque eram crianças cruéis e que não tinham carinho em casa como eu tinha. Mas quando ia dormir depois dela, chorava de novo. Todo dia era isso. Pedia para Deus me levar. (Funcionária 2)
}

O trecho sugere algo típico da nossa sociedade, o ato de julgar as pessoas baseado na aparência. As pessoas que fogem daquilo que a sociedade dita como "padrão" são consideradas inferiores. Isso remonta ao conceito de cultura, uma vez que ela conduz às ações dos indivíduos, funcionando como um padrão coletivo de identificação dos grupos (PIRES; MACÊDO, 2006). Por advir da cultura, esse 
tipo de atitude já se manifesta no comportamento da criança. Nota-se que a conscientização sobre a diversidade deve ser um tema trabalhado dentro das escolas, evitando-se assim os estereótipos. A narrativa da Funcionária 2 afirma que ela foi vítima de estigmas. O desconforto era tanto que, em certos momentos, desejava a morte. Goffman (2008) esclarece que o estigma pode causar danos negativos na vida da vítima.

Os relatos sobre a história de vida dos funcionários revelaram um dado interessante. Tanto o Funcionário 1 quanto a Funcionária 2 citam a mídia como agente de mudança.

Quando acabei a escola, ficava o dia em casa sem fazer nada. Vi uma reportagem na televisão sobre pessoas que conseguiam superar as dificuldades, pessoas de cadeira de rodas que viviam a vida e mostravam que era possível trabalhar e ter uma vida. (Funcionária 2)

A Funcionária 2 se sentiu estimulada a ingressar no mercado de trabalho após assistir a essa reportagem. A matéria exibiu pessoas com deficiência física que conseguiram superar suas limitações e ter uma vida de qualidade. Percebe-se que a mídia foi capaz de mudar a percepção que ela tinha de si mesma, revelando que a deficiência não era empecilho para se exercer uma profissão.

Sei que tem muita gente preconceituosa por aí. Mas sempre tem uma novela que mostra a nossa realidade e acho que as pessoas vão se tocando que não somos monstros e nem coitados. Alguns nascem assim e outros podem ficar assim. Ninguém está livre. (Funcionário 1)

A fala do Funcionário 1 sugere que a novela tratou com realismo o preconceito que a PCD enfrenta no dia a dia. Ele acredita que as novelas contribuem para desmitificar que a PcD é digna de pena. Já o ato de classificar a deficiência como monstruosidade é um preconceito arcaico, que se originou como os romanos (BAHIA, 2006; PEREIRA, 2006).

Dessa forma, a mídia apresenta um papel importante na sociedade. É um meio de comunicação que alcança as massas. Portanto ela é capaz de promover a conscientização da sociedade sobre temas de interesse coletivo, como o caso das pessoas com deficiência. ${ }^{2}$

\section{O SENTIDO DO TRABALHO}

O trabalho revelou ser o sentido da vida desses profissionais, conforme foi discutido no referencial teórico. A PCD tende a dar mais importância ao trabalho, pois the atribui a oportunidade de ter independência financeira. Segundo Fleig et al. (2005), estar desempregado acarreta a escassez de recursos financeiros gerando, consequentemente, conflitos sociais. Esses conflitos decorrem do fato de o sujeito não conseguir atender às suas próprias necessidades, muito menos dos seus familiares. Ainda, segundo a referida autora (FLEIG et al., 2005, p. 85), o desemprego gera:

(...) incerteza dos valores, abala a identidade, causa distúrbios psicológicos, pois ele é retratado como eixo orientador da ação social do homem, principalmente nas mediadas pelo dinheiro. A falta do emprego inibe parcialmente a interação social.

Além da questão financeira, Giordano (2000) e Fleig (et al.,2005) acrescentam que o trabalho oferece autorrealização e autoestima ao indivíduo. As narrativas corroboram com a visão dos autores.

Trabalhando a gente se sente vivo. Sente que faz parte da sociedade. Prova para as pessoas que também podemos produzir. (...) Então quando a gente trabalha consegue ganhar o respeito dos outros. (Funcionário 1)

O trecho elucida que o trabalho é que dá razão à vida. O Funcionário 1 entende que a aceitabilidade social só é adquirida por meio do trabalho. Por ser estigmatizada como inválida, a PCD busca provar para a sociedade que é capaz de produzir como qualquer outro indivíduo.

Antes eu pensava que eu nunca ia conseguir arrumar um emprego e que não ia conseguir fazer nada. Ficava muito tempo sozinha vendo televisão. Era triste. Eu me sentia inferior. Mas quando comecei a trabalhar, vi que era normal, que só tinha uma doença, mas podia viver com ela. Acho que o trabalho faz com que a gente se sinta valorizado, útil. A gente acaba ganhando independência e isso é muito bom mesmo. (Funcionária 2)

2 A novela citada pelo Funcionário 1 foi Viver a Vida, exibida pela Rede Globo em horário nobre. 
O discurso da Funcionária 2 reafirma o valor do trabalho para o indivíduo. Sem ele, a pessoa se sente inferior em relação às demais pessoas. Ela relaciona a normalidade ao trabalho, elucidando que, ao se inserir no mercado de trabalho, sentiu-se "normal". A Funcionária 2 relata que percebeu que poderia trabalhar, apesar de sua deficiência. Ela passou a se sentir útil na sociedade. A fala da funcionária corrobora com a visão de Ardichvili e Kuchinke (2009), que afirma que a pessoa vê o trabalho como valor que tem de si mesmo. Castelhano (2005) acredita que o trabalho invade a vida do sujeito, constituindo-se de um elemento fundamental na construção de sua identidade.

Além das respostas dos funcionários, analisou-se também a visão do gestor sobre o sentido do trabalho para pessoas com deficiência.

Eu acredito que elas se sentem incluídas. Elas acreditam que realmente podem fazer a diferença, podem crescer, podem sustentar uma casa, podem ajudar um parente (...) quando acontece um acidente, quando a pessoa nasce deficiente, muitos sentem depressão, se sentem inúteis, incapacitados. Eu acho isso realmente importante porque ninguém merece, ninguém merece um fardo tão pesado de se sentir inútil, de se sentir incapaz. (Gestor 1)

Seu discurso sugere que a PCD se sente inserida na sociedade por meio do trabalho. Na visão do gestor, ser produtivo está intimamente ligado ao ato de trabalhar. Ele acredita que o labor contribui para que a PcD não tenha sentimentos depreciativos com relação a si próprio. Essa discussão vai de encontro com o que foi apresentado por Ardichvili e Kuchinke (2009), pois os relatos evidenciam que o trabalho é capaz de recuperar a autoestima desses indivíduos, uma vez que eles de sentem úteis por executarem um labor auxiliando, assim, no sustento familiar.

\section{OBRIGAÇÃO LEGAL}

Com base no referencial teórico, buscou-se saber os motivos que levaram a organização a contratar pessoas com deficiência. Algumas organizações contratam por questão de responsabilidade social e outras contratam apenas por obrigação legal. Os resultados revelaram que a organização estudada contrata pessoas com deficiência com o propósito de cumprir a lei.

Bom, a princípio, sinceramente é a lei. A lei diz que a gente tem que contratar. (...) Não é, sinceramente, a primeira coisa que vem a cabeça do gestor contratar alguém que tenha alguma deficiência. (Gestor 1)

Gestor 1 afirma que a contratação de PcD é feita por razão coercitiva. O fragmento sugere que a imposição legal e o receio de penalidade, caso a lei não seja cumprida, são os fatores motivacionais para a contratação de profissionais com deficiência (SARAIVA; IRIGARAY, 2009). O Gestor 1 justifica que os gestores não pensam em contratar pessoas com deficiência. A narrativa indica que o posicionamento dos gestores pode estar pautado na visão errônea e discriminatória de que a PCD é improdutivo. Desconstruir essa imagem é um dos grandes desafios da sociedade (BAHIA, 2006). Os resultados ainda revelam que os funcionários têm consciência do real motivo de sua contratação.

Acho muito boa (as leis de cotas) porque é muito difícil conseguir emprego na nossa situação então ajuda, né? Mas a gente sabe que é por obrigação, sabe? Eu não ligo desde que eu tenha um trabalho e me tratem como uma pessoa normal porque é isso que sou (Funcionária 2)

A Funcionária 2 relata a dificuldade que o profissional com deficiência tem para se inserir no mercado de trabalho. Ela compreende que atua no hotel por imposição da lei, porém não se incomoda, desde que haja respeito entre os profissionais. O fragmento sugere que a funcionária não deseja ser tratada de modo especial, mas sim de modo igualitário. Este elemento vai de encontro com uma discussão acadêmica e prática que gera opiniões bastante divergentes: a questão da valorização ou da dissolução das diferenças ao tratar-se de diversidade organizacional (PEREIRA; HANASHIRO, 2010). A primeira abordagem, como o próprio nome sugere, tende a valorizar e a realçar as diferenças entre as pessoas a partir das características grupais a que os indivíduos pertencem, como: raça, gênero, religião, etc. Portanto se busca criar políticas empresariais que venham a atender a cada uma dessas peculiaridades. Em contrapartida, a abordagem da dissolução das diferenças parte para um estilo de gestão em que "não importa quem o indivíduo é ou quais características tem, o que importa é que ele seja competente e efetivo na geração de resultados para a organização" 
(PEREIRA; HANASHIRO, 2010). Essa discussão remete a outro assunto - a lei de cotas. Abaixo segue a opinião de um dos entrevistados sobre essa obrigação legal.

Tem muita gente deficiente que tem preconceito com elas (as cotas). Eu não tenho. Sei que se estou aqui é graças a elas. Não me importo se me contrataram para cumprir a lei. (Funcionário 1)

Funcionário 1 relata a rejeição da cota por parte de algumas pessoas com deficiência, reforçando a visão de Pereira e Hanashiro (2010) de que a PCD teme ser vítima do estigma ao se inserir no mercado de trabalho por meio das cotas. Mas o Funcionário 1 não demonstra pensar dessa forma. Apesar de saberem que são contratados pela imposição da "Lei de cotas", os funcionários a consideram uma boa ferramenta para se inserir no mercado de trabalho. As narrativas elucidam que eles avaliam como mais importante o direito ao trabalho, desconsiderando os reais motivos que geraram a contratação.

\section{POSSÍVEIS FORMAS DE BURLAR A LEI}

Pode-se burlar a lei das seguintes formas: oferecer vagas para PCD que exijam um alto grau de qualificação, contratar pessoas com uma leve deficiência e alegar dificuldade de acessibilidade e adequação ao trabalho (CARNEIRO; RIBEIRO, 2008; CARVALHO-FREITAS, 2007). A análise de conteúdo revelou que a organização apresenta ações que podem ser interpretadas como uma forma sutil de se burlar a lei.

Nós temos duas pessoas que têm problema na perna e trabalham normalmente. Demonstram muita qualidade no serviço também e... como se realmente nem tivesse a deficiência. (Gestor 1)

A narrativa do Gestor 1 revela que existem dois funcionários que possuem uma leve deficiência. Apesar de o gestor elogiar o desempenho profissional de ambos, seu discurso sugere que a organização emprega profissionais cuja deficiência possa ser camuflada. Supõe-se que a organização contrata pessoas com base no conceito de "normalidade" e "boa aparência", revelando uma postura discriminatória (BANDEIRA; BATISTA, 2002). Dessa forma, busca-se agregar profissionais que possuam deficiências pouco complicadas (BAHIA, 2006) e muitas vezes imperceptíveis.

Eu tenho um probleminha na perna, mas olhando para mim é meio imperceptível, sabe? Só manco um pouquinho e então nunca sofri com preconceito nem nada disso. Mas acho que é porque eu pareço normal. (Funcionária 2)

O discurso da Funcionária 2 afirma que nunca sofreu preconceito dentro do hotel, pois sua deficiência não é notável. A entrevistada sugere que isso se deve ao fato de aparentar ser uma pessoa sem deficiência, a qual ela adjetiva como normal.

Foi ainda pequena que perdi parte da audição. Ouço pouco e falo bem. (Funcionária 3)

A narrativa da Funcionária 3 revela que ela possui deficiência auditiva que pode ser classificada como pouco complicada e imperceptível, reiterando a questão da "normalidade". Conforme salientado nas falas, os funcionários que atuam nessa organização possuem uma leve deficiência. A Funcionária 3 , que trabalhou na organização durante anos, também apresenta as mesmas características que os demais. Os fragmentos da Funcionária 2 e da Funcionária 3 reafirmam o discurso do Gestor 1 de que, é "como se realmente nem tivesse a deficiência". De forma que se pode questionar a razão pela qual só há profissionais com deficiência leve na organização.

Quando o gestor foi questionado sobre as principais dificuldades para a inserção de PcD na empresa, seu discurso denota que alguns tipos de deficiência são privilegiados devido à dificuldade de adequação aos cargos.

Principal dificuldade é conseguir realmente que alguma deficiência se encaixe com a correria
de hotel. Existem alguns empecilhos. Por exemplo, deficiência visual a gente não tem nenhuma
vaga. Não conseguiria encaixar alguém com deficiência visual em um hotel, por exemplo. (...)
Procurar algumas pessoas que possam exercer de uma maneira natural, né, normal, alguma
atividade de hotel sem prejudicá-lo primeiramente e juntamente sem perder o ritmo dos hotéis
sempre muito corrido. (Gestor 1 )

A justificativa de que não haveria como "encaixar alguém com deficiência visual em um hotel" pode ser encarada como uma desculpa. A pessoa com deficiência visual poderia ser alocada em um 
cargo em que a visão não fosse condição necessária para se desempenhar determinada função, como, por exemplo, uma telefonista. A declaração do gestor faz referência novamente ao termo "normal" em conjunto com o termo "natural". Dessa forma, o discurso do gestor insinua que a empresa busca contratar profissionais com a menor deficiência possível, a fim de ser mascarada. O Gestor 1 faz uma relação entre produtividade e contratação de profissional com deficiência, elucidando que as políticas de cotas podem prejudicar o desempenho do hotel. Dessa forma, os fragmentos sugerem que a empresa Alfa adote essas práticas a fim de burlar a lei.

Esse debate aponta o quanto muitas organizações brasileiras ainda possuem uma postura imatura com relação à contratação de profissionais com deficiência, visto que a contratação decorre exclusivamente da necessidade de se cumprir a lei em vigor (CARNEIRO; RIBEIRO, 2008). Assim, por meio da prática do "jeitinho brasileiro", contratam-se sujeitos que possuem deficiências "pouco complicadas" (BAHIA, 2006).

\section{ACESSIBILIDADE}

Nesse trabalho, entende-se por acessibilidade a não existência de barreiras arquitetônicas, instrumental, comportamentais e atitudinais para PCD (BAHIA; SCHOMMER, 2009). O gestor mencionou que a estrutura do hotel foi planejada para atender pessoas com deficiência.

Estrutural a gente já tem. A nossa entrada não tem degrau então já é de acessibilidade e os apartamentos também. A gente tem os banheiros, vestiários, já são todos adaptados. (Gestor 1)

Tal discurso foi confirmado pelos funcionários. Dessa forma, não foram encontradas barreiras arquitetônicas.

(...) Aqui o acesso é fácil. A entrada tem uma rampa e isso facilita a minha vida. (Funcionário 1)

A análise das falas revelou a presença da barreira instrumental. Ela se refere aos instrumentos e aos utensílios de trabalho (BAHIA; SCHOMMER, 2009).

Não tem como colocar, por exemplo, alguém que tenha deficiência visual para fazer reservas. Não têm sistemas, computadores em braile. (Gestor 1)

A organização não oferece vaga de emprego para pessoas com deficiência visual, alegando que não possuem os recursos necessários para que ela possa atuar dentro da empresa. Vale lembrar que é de responsabilidade das organizações oferecerem vagas de emprego e os meios necessários para que a PCD possa ser incluída na empresa (BAHIA; SCHOMMER, 2009). Bahia (2006) alerta que o trabalho é um direito da PcD. A contratação deve ocorrer sempre que o profissional tiver a qualificação necessária para atuar no cargo, independente de sua deficiência.

Quanto às dimensões comportamentais e atitudinais, a organização oferece um programa de diversidade no qual todos os funcionários, com ou sem deficiência, devem participar.

Existe um treinamento que se chama Naturalmente Diferentes. Ele fala das diversidades não só físicas, né? As deficiências físicas. Diversidades de opinião, de orientação sexual, de raça, de nacionalidade e etc. (...) E acho que ajuda para a imagem coorporativa da empresa. (Gestor 1)

De acordo com o gestor, o programa Naturalmente Diferentes engloba todos os tipos de diversidade, com o objetivo de conscientizar os profissionais a respeito das individualidades de cada pessoa. Percebe-se que a empresa busca promover um ambiente acolhedor para os profissionais. O gestor acredita que este programa contribui para imagem coorporativa positiva da empresa.

Eles fazem questão de dizer que não há diferença entre nenhum de nós. Essas diferenças que eles falam é sobre cor de pele, nível de escolaridade, opção sexual e pessoas como eu que são deficientes. A gente abraça a ideia porque no fim das contas nós somos pessoas. (Funcionário 1)

A narrativa do Funcionário 1 remete à teoria de Saraiva e Irigaray (2009), que observam que as organizações buscam se legitimar perante a sociedade utilizando o discurso. Pode ser que a organização utilize a imagem de socialmente responsável a fim de se promover, como elucida o fragmento do Gestor 1. 
Aqui a gente tem umas palestras para aceitar as diferenças. Tratar com igualdade as pessoas como eu, gente negra, pobre e os gays. Todo mundo aqui é igual. (Funcionária 2)

O relato da Funcionária 2 denota que não há distinção entre os funcionários devido às suas diferenças. A empresa Alfa usa esse discurso como política empresarial quando se trata de apenas o cumprimento de uma obrigação legal (SARAIVA; IRIGARAY, 2009).

O programa Naturalmente Diferentes é aplicado em todos os hotéis da rede Alfa no Brasil. Ele tem como objetivo direcionar comportamentos, a fim de combater a discriminação em todas as suas formas dentro do ambiente de trabalho. Os funcionários consideram importante o empenho da organização em propagar um ambiente saudável.

\title{
DISCRIMINAÇÃO
}

É importante esclarecer que, no momento em que as questões referentes à discriminação foram feitas, houve um desconforto por parte dos entrevistados. Alguns gaguejaram e outros olhavam ao redor para ver se não havia alguém por perto, antes de responder às perguntas. Tal comportamento revela a delicadeza que o tema discriminação carrega.

Nessa categoria, a análise de conteúdo revelou que a pessoa com deficiência percebe que há muita discriminação no dia a dia.

\begin{abstract}
Quando a gente é deficiente as pessoas nos tratam diferente. Alguns falam alto com você como se você fosse surdo. (...) Ninguém quer contratar gente inválida como muitos dizem. Somos vistos como um peso. (...) Não vou mentir, passei por muitos momentos complicados porque as pessoas não toleram gente diferente. Eles nem sequer buscam conhecer você e já tem uma opinião formada sobre você. Já é ruim ser deficiente. Tem noção do que passei por ser deficiente e negro?" (Funcionário 1)
\end{abstract}

O relato do Funcionário 1 sugere que as pessoas não sabem como lidar com a deficiência. Esse distanciamento e até a "falta de tato" para se lidar com o indivíduo que possui deficiência advém da antiguidade, já que há alguns anos as limitações físicas, mentais ou sensoriais eram interpretadas como uma espécie de invalidez ou incapacidade do próprio indivíduo (BAHIA, 2006; PEREIRA, 2006).

Fruto dessa carga histórica, algumas pessoas tratam a PcD de forma diferente, pois acreditam que ela necessita de um cuidado especial. Não se trata de um ato de discriminação intencional, porém tal postura incomoda a pessoa que possui deficiência. Dessa forma, a PcD associa esse tratamento à discriminação. O discurso do Funcionário 1 evidencia que as pessoas atribuem a deficiência à invalidez. É um conceito arraigado na sociedade que advém da antiguidade e que persiste até os dias atuais. A narrativa elucida que a capacidade da PcD muitas vezes é questionada reafirmando que as pessoas com deficiência são vítimas de estigmas e discriminação. O discurso explicita que as pessoas pertencentes às minorias são prejulgadas com base em suas diferenças e não como sujeito. O Funcionário 1 sugere que já foi vítima de discriminação em vários momentos de sua vida e exprime sentimento de mágoa, pois percebe que é vítima de dupla discriminação, por ser negro e deficiente físico.

Com relação ao ambiente de trabalho, os entrevistados garantem que não há evidências de atos discriminatórios.

Você perguntou se eu já presenciei alguma situação de discriminação, eu nunca presenciei. E eu acredito piamente que nunca houve. Porque, né, isso é uma questão muito forte. (...) O deficiente muitas vezes não consegue esconder, ele expressa isso chorando, conversando com alguém. $\mathrm{E}$ a história sempre chega, né? Então eu acho que nunca aconteceu. (Gestor 1)

O Gestor 1 acredita que os funcionários com deficiência não sofrem discriminação dentro do hotel por nunca ter havido queixa. Segundo ele, a PcD não consegue guardar o sentimento de mágoa para si. Ela tende a se desabafar com alguém. $O$ gestor elucida que se houvesse ocorrido tal fato, a administração do hotel saberia, pois não há como esconder um ato de discriminação. Todos os funcionários apresentaram a mesma opinião ao serem questionados sobre o assunto.

Todo mundo aqui é igual. A gente recebe o mesmo tratamento, não tem frescura. (Funcionária 2) 
A narrativa da Funcionária 2 confirma a afirmação do gestor de que, os funcionários são tratados de forma igualitária. No entanto, ao analisar com mais cuidado as narrativas, é possível captar uma contradição no discurso do Gestor 1, que sugere que há discriminação, ainda que de forma sutil.

(Não há) nenhuma diferença na apresentação de um colaborador da cota ou normal. E nunca tivemos problema de discriminação, de nada. Pelo contrário, sabe? É anunciado que a pessoa faz parte da cota e tal e a equipe acolhe de maneira até melhor. (Gestor 1 )

Em vários momentos, o gestor se refere aos funcionários com deficiência como os "da cota". Tal expressão sugere que há uma segregação dentro da empresa pelo menos do ponto de vista administrativo. A narrativa dá a entender que é como se houvesse dois tipos de funcionários: os "da cota" e os intitulados "normais". Tal nomenclatura condiz com a concepção de deficiência baseada na normalidade como matriz de interpretação, de modo que a deficiência é vista com um desvio da normalidade (CARVALHO-FREITAS: MARQUES, 2010). A segregação dos funcionários é tão sutil que eles não percebem a sua existência dentro da organização. Conforme Bandeira e Batista (2002) salientam, a discriminação pode se manifestar de forma sutil e mascarada.

O fragmento "é anunciado que a pessoa faz parte da cota e tal" contradiz o discurso não discriminatório do gestor, pois destoa da sua afirmação de que não há diferenciação na apresentação dos funcionários. Por que anunciar que a pessoa se inseriu na organização por meio da cota? Não seria esta uma manifestação de discriminação sutil? O gestor sugere que tal posicionamento busca evitar que haja atitudes discriminatórias. Já o trecho "e a equipe acolhe até melhor" elucida que há uma diferenciação no tratamento dos funcionários com e sem deficiência, remetendo à ideia de que a PcD necessita de um tratamento especial devido à sua "limitação".

A discriminação é crime de acordo com a lei brasileira. No entanto o seu combate demanda tempo, já que se trata de um comportamento cultural de precedentes históricos. Conforme visto, a discriminação está presente tanto no dia a dia como também se manifesta no âmbito do trabalho, mesmo que de forma sutil.

\section{CONSIDERAÇÕES FINAIS}

O presente estudo teve como objetivo compreender as políticas de gestão de pessoas voltadas para pessoas com deficiência em um empreendimento hoteleiro. Por ser um tema recente nas pesquisas acadêmicas, considerou-se pertinente estudá-lo.

Os principais resultados revelaram que a empresa Alfa possui o discurso de valorização da diversidade em seu ambiente de trabalho. Por meio do programa Naturalmente Diferentes, o hotel Alfa dissemina a importância de se respeitar as diversas diferenças dentro da empresa. Embora esse discurso seja posto em prática pelos funcionários, observou-se que, talvez, haja um preconceito mascarado por parte da administração do hotel, a qual realiza de forma sutil a segregação dos funcionários.

Observou-se que a organização utiliza o discurso para se legitimar perante a sociedade. A inserção de pessoas com deficiência e a valorização da diversidade é explanado como uma das políticas organizacionais da empresa. Assim, o ser socialmente responsável é vinculado à imagem da empresa. Contudo é pertinente esclarecer que tais políticas organizacionais são, na verdade, o cumprimento da lei. A empresa Alfa contrata profissionais com deficiência por obrigação legal e não por iniciativa própria ou responsabilidade social, como demonstram os discursos. Com relação à contratação de profissionais com deficiência na rede Alfa, os resultados sugerem que há indícios de que a organização estudada se utiliza de meios para burlar a lei, haja vista que se busca contratar funcionários com leve deficiência. Além disso, a organização privilegia a deficiência física no processo de recrutamento e seleção, alegando a dificuldade de adequação ao cargo.

Com relação à discriminação fora do ambiente de trabalho, notou-se que os funcionários são vítimas de atos discriminatórios desde a infância. Eles são estigmatizados como inválidos e sofrem por serem assim classificados. Dessa forma, reconhecem o trabalho como uma forma de se validar perante a sociedade. Os profissionais com deficiência relacionam o trabalho com a independência financeira e com o sentimento de pertença à sociedade. 
Descobriu-se que os profissionais com deficiência atribuem à mídia o papel de agente de mudança social, já que ela busca conscientizar os cidadãos a respeito da diversidade. Os funcionários sugerem que ela tem a capacidade de construir e descontruir os mitos referentes à PcD. A mídia, portanto, pode ser uma grande aliada ao combate ao preconceito. Após algumas produções televisivas, os funcionários perceberam que as atitudes discriminatórias diminuíram, porém revelam que elas ainda persistem no âmago da sociedade.

Com base nos resultados, pode-se dizer que a pesquisa não se limita apenas ao campo acadêmico, pois abrange os interesses da sociedade como um todo. A importância dessa pesquisa foi reconhecida pelo Funcionário 1, que se expressou da seguinte forma: "acho importante essa pesquisa porque mostra que tem gente que se importa com a nossa vida", revelando a contribuição da pesquisa para a comunidade. Verifica-se que este trabalho tem relevância para o campo do turismo, visto que há poucos estudos acadêmicos que abordam a inserção dos profissionais com deficiência nos empreendimentos turísticos.

Durante toda a elaboração dessa pesquisa surgiram limitações, sendo em maior grau as referentes à inserção ao campo. As organizações se recusaram a participar da pesquisa quando tomaram conhecimento do assunto estudado. Pode-se dizer que o próprio assunto estudado se caracterizou como barreira ao campo, dado seu contexto polêmico. A única empresa que concordou em participar da pesquisa solicitou que as entrevistas não fossem gravadas. Dessa forma, o registro foi feito por meio de anotações. Sendo esta mais uma limitação ao estudo, visto que é impossível registrar integralmente todas as informações por meio de anotações. Finalmente, como última limitação, verifica-se que a lei de cotas e a contribuição de apenas uma organização tornaram a amostra de entrevistados bastante limitada.

Visto que existem poucas pesquisas referentes ao tema proposto, podem ser desenvolvidos mais estudos que explorem a temática das minorias nos empreendimentos turísticos. Sugere-se uma pesquisa que vise analisar os impactos negativos que a discriminação pode causar tanto na vida profissional quanto na vida pessoal do funcionário pertencente às minorias.

Por fim, conclui-se que o hotel Alfa, por possuir forte presença no mercado, pode servir de exemplo de empresa que valoriza as diferenças, cumprindo o papel de ator social. Apesar de terem sido levantados alguns pontos com relação ao modelo de gestão da diversidade no hotel, se deve esclarecer que a organização insere profissionais com deficiência e busca promover um ambiente saudável dentro da instituição.

Conclui-se que a contração desses profissionais traz diversos benefícios para a organização. Além do ganho de uma imagem corporativa positiva, acrescenta-se a possibilidade de aprender a lidar com a diversidade organizacional. No entanto vale mencionar que a inserção de profissionais com deficiência ainda se apresenta como um grande desafio para os gestores das empresas, para as pessoas com deficiência e para os colegas de trabalho.

\section{REFERÊNCIAS}

ALVES, M. A.; GALEÃO-SILVA, L. G. A crítica da gestão da diversidade nas organizações. RAE - Revista de Administração de Empresas, vol. 44, n. 3, jul./set. 2004, p. 20 - 29.

ARDICHVILI, A.; KUCHINKE, K. P. International perspectives on the meanings of work and working: current research and theory. Advances in Developing Human Resources, Thousand Oaks, v. 11, n. 2, p.155-167, Apr. 2009.

ASHLEY, P. A. (Org.) Ética e responsabilidade social nos negócios. São Paulo: Saraiva, 2002.

BAHIA, M. S. Responsabilidade social e diversidade nas organizações: contratando pessoas com deficiência. Rio de Janeiro: Qualitymark, 2006.

BAHIA, M. S.; SCHOMMER, P. C. Inserção profissional de pessoas com deficiência: aprendendo com as práticas cotidianas de uma experiência empresarial. In: ENCONTRO DA ASSOCIAÇÃO NACIONAL DE PÓS-GRADUAÇÃO E PESQUISA EM ADMINISTRAÇÃO, 33, 2009, São Paulo. Anais... São Paulo: ANPAD, 2009. 1 CD-ROM

BANDEIRA, L. BATISTA, A. S. Preconceito e discriminação como expressões de violência. Revista de estudos feministas, vol. 10, n. 1, 2002, p. 119-141. 
BARDIN, L. Análise de conteúdo. 3. ed. Lisboa: Edições 70, 2011.279p.

BRASIL. Lei no 8.213, de 24 de julho de 1991. Disponível em: <http://www.planalto.gov.br/ccivil_03/ Leis/L8213cons.htm> Acesso em 27/01/2012.

BRASIL. Decreto no 3.298, de 20 de dezembro de 1999. Disponível em <http://www.planalto.gov. br/ccivil_03/decreto/D3298.htm>. Acesso em: 26/01/2012.

BROOKS, A. K.; EDWARDS, K. Allies in the workplace: including LGBT in HRD. Advances in Developing Human Resources, Thousand Oaks, v. 11, n.1, p. 136-149, Feb. 2009.

CAMPBELL, J. Valuing diversity: the disability agenda, we've only just begun. Disability and Society, London, v. 17, n. 4, p. 471-478, June 2002.

CARNEIRO, R.; RIBEIRO, M. A. A inclusão indesejada: as empresas brasileiras face à lei de cotas para pessoas com deficiência. In: ENCONTRO DA ASSOCIAÇÃO NACIONAL DE PÓS-GRADUAÇÃO E PESQUISA EM ADMINISTRAÇÃO, 32, 2008, Rio de Janeiro. Anais... Rio de Janeiro: ANPAD, 2008. 1 CD-ROM

CARVALHO-FREITAS, M. N. de. A inserção de pessoas com deficiência nas empresas brasileiras: um estudo sobre as relações entre concepções de deficiência, condições de trabalho e qualidade de vida no trabalho. 2007. 314 f. Tese (Doutorado) - Curso de Administração, Departamento de Centro de Pós-graduação e Pesquisas em Administração da Faculdade de Ciências Econômicas, Universidade Federal de Minas Gerais, Belo Horizonte, 2007.

CARVALHO-FREITAS, M. N. de.; NEPOMUCENO, M. F.; SUZANO, J. C. C.; ALMEIDA, L. A. D. Socialização organizacional de pessoas com deficiência. In: ENCONTRO DA ASSOCIAÇÃO NACIONAL DE PÓS-GRADUAÇÃO E PESQUISA EM ADMINISTRAÇÃO, 33, 2009, São Paulo. Anais... São Paulo: ANPAD, 2009. 1 CD-ROM

CARVALHO-FREITAS, M. N. de; MARQUES, A. L. Construção e validação de instrumentos de avaliação da gestão da diversidade: a inserção no trabalho de pessoas com deficiência. In: ENCONTRO DA ASSOCIAÇÃO NACIONAL DE PÓS-GRADUAÇÃO E PESQUISA EM ADMINISTRAÇÃO, 30., 2006, Salvador. Anais... Salvador: ANPAD, 2006. 1 CD-ROM

CHURCHILL, G. A. Jr; PETER, J. P. Marketing: criando valor para os clientes. 2. ed. São Paulo: Saraiva, 2000.

DAFT, R. L. Administração. 4. ed. Rio de Janeiro: LTC, 1999.

DRUCKER, P. F. Fator humano e desempenho: o melhor de Peter Drucker sobre administração. São Paulo: Pioneira Thomson Learning, 2002.

EMSLIE, C.; HUNT, K. 'Live to work' or 'work to live'?: a qualitative study of gender and work life balance among men and women in mid-life. Gender, work and organization, Oxford, v. 16, n. 1, p. 151-172, Jan. 2009.

FLEIG, D. G; PEREIRA, M. C; GRZYBOVSKI, D; BRITO, M. J. Reestruturação produtiva e subjetividade: análise interpretativa do significado do desemprego. Organizações e Sociedade, v. 12, n. 33, abr./jun. 2005, p.71-91.

GIORDANO, B. W. (D)eficiência e trabalho: analisando suas representações. São Paulo: Fapesp, 2000.

GODOI, C.K.; BALSANI, C.P.V. A pesquisa qualitativa nos estudos organizacionais brasileiros: uma análise bibliométrica. In: GODOI, C.K.; BANDEIRA-DE-MELLO, R.; SILVA, A. B. da (Org.). Pesquisa qualitativa em estudos organizacionais: paradigmas, estratégias e métodos. São Paulo: Saraiva, 2006. p. 89-112.

GOFFMAN, E. Estigma: notas sobre a manipulação da identidade deteriorada. 4 ed. Rio de Janeiro: LTC, 2008.

HANASHIRO, D. M. M; TEIXEIRA, M. L. M; ZACARELLI, L. M. Gestão do fator humano: uma visão baseada em stakeholders. 2. ed. São Paulo: Saraiva, 2008.

INSTITUTO de Ethos de Empresas e Responsabilidade Social - ETHOS. O que é RSE. Disponível em: <http://www1.ethos.org.br/EthosWeb/pt/29/o_que_e_rse/o_que_e_rse.aspx>. Acesso em: 09 de mar. 2011. 
MYERS, A. O valor da diversidade racial nas empresas. Estudos afro-asiáticos, Rio de Janeiro, v. 25, n. 3, p. $483-515,2003$.

NERI, M. et al. Retratos da deficiência no Brasil. Rio de Janeiro: FGV/IBRE, 2003.

NKOMO, S. M.; COX JUNIOR, T. Diversidade e identidade nas organizações. In: CLEGG, S. R.; HARDY, C.; NORD, W. R. (Org.). Handbook de estudos organizacionais: modelos de análise e novas questões em estudos organizacionais. São Paulo: Atlas, 2007. p. 332-358.

PEREIRA, R. J. Anatomia da diferença: uma investigação teórico-descritiva da deficiência à luz do cotidiano. 174 f. Tese (Doutorado) em saúde pública, Escola Nacional de Saúde Pública Sérgio Arouca, Fundação Oswaldo Cruz, Rio de Janeiro, 2006.

PEREIRA, R. J; HANASHIRO, D. M. M. Ser ou não ser favorável às práticas de diversidade? Eis a questão. RAC - Revista de Administração Contemporânea, Curitiba, v. 14, n. 4, jul./ago. 2010, p. 670 - 683.

PIRES, J. C. S.; MACÊDO, K. B. Cultura organizacional em organizações públicas no Brasil. Revista de Administração Pública, Rio de Janeiro, v. 40, n. 1, p. 81-105, jan./fev. 2006.

REIS, C. N. (org.) O sopro do minuano: transformações societárias e políticas sociais - um debate acadêmico. Porto Alegre: EDIPUCRS, 2007.

SANTOS, W. R. Pessoas com deficiência: nossa maior minoria. Revista de Saúde Coletiva, Rio de Janeiro, v. 18 , n.3, 2008, p. 501-519.

SARAIVA, L. A. S.; IRIGARAY, H. A. dos R. Políticas de diversidade nas organizações: uma questão de discurso? RAE - Revista de Administração de Empresas, v.49, n.3, 2009, p.337 - 348.

SASSAKI, R. K. Termologia sobre deficiência na era da inclusão. Revista Nacional de Reabilitação, São Paulo, ano 5, n. 24, jan/fev., 2002, p. 6-9.

SCOTT, J. O enigma da igualdade. Estudos feministas, Florianópolis, v. 13, n. 1, p. 11-30, jan./abr. 2005.

SHORE, L. M. et al. Diversity in organizations: where are we now and where are we going? Human Resource Management Review, Greenwich, v. 19, n. 2, p. 117-133, June 2009.

SOBRAL, F; PECI, A. Administração: teoria e prática no contexto brasileiro. São Paulo: Pearson, 2008.

TACHIZAWA, T.; ANDRADE, R. O. B. de. Gestão socioambiental: estratégias na nova era da sustentabilidade. Rio de Janeiro: Elsevier, 2008.

TRIVIÑOS, A.N.S. Introdução à pesquisa em ciências sociais: a pesquisa qualitativa em educação. São Paulo: Atlas, 1987. 175 p.

VIEIRA, M. F; OLIVEIRA, M. B. Administração contemporânea: perspectivas estratégicas. São Paulo: Atlas, 1999.

VILLE, I.; WINANCE, M. To work or not to work?: the occupational trajectories of wheelchair users. Disability \& Rehabilitation, London, v. 28, n. 7, p. 423-436, Apr. 2006.

WAGNER III, J. A; HOLLENBECK, J. R. Comportamento organizacional: criando vantagem competitiva. São Paulo: Saraiva, 2003

WARD, J.; WINSTANLEY, D. Watching the watch: the UK fire service and its impact on sexual minorities in the workplace. Gender, Work and Organization, Oxford, v. 13, n. 2, p. 193-219, Mar. 2006. 